Supporting Information

of

\title{
Redox-Active Micelle-Based Reaction Platforms for In Situ Preparation of Noble Metal Nanocomposites with Photothermal Conversion Capability
}

\author{
Jiayi You ${ }^{1}$, Lingshan Liu ${ }^{1}$, Wanqiu Huang ${ }^{1}$, Ian Manners ${ }^{2}$, Hongjing Dou*1 \\ 1 The State Key Laboratory of Metal Matrix Composites, School of Materials Science and \\ Engineering, Shanghai Jiao Tong University, Shanghai 200240, P. R. China \\ *e-mail: hjdou@sjtu.edu.cn \\ 2 Department of Chemistry, University of Victoria, Victoria, British Columbia V8P 5C2, Canada
}




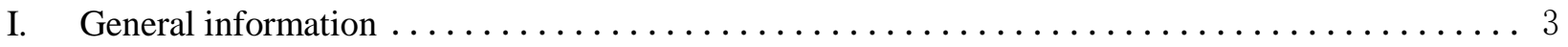

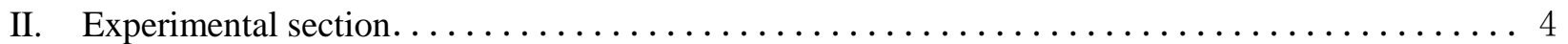

III. Characterization of $\mathrm{PFMVS}_{98} \ldots \ldots \ldots \ldots \ldots \ldots \ldots \ldots \ldots \ldots \ldots \ldots \ldots \ldots \ldots$

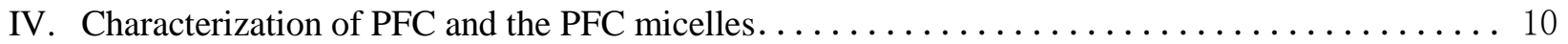

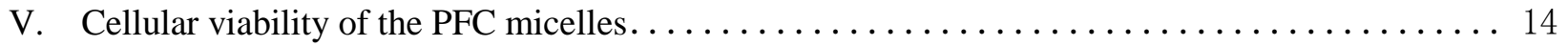

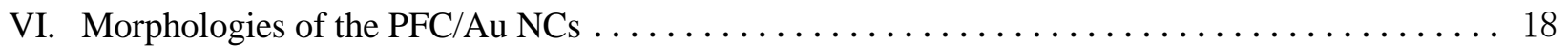

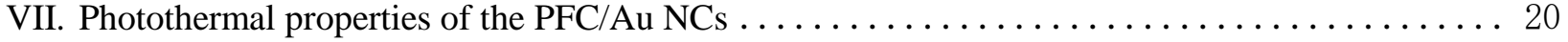

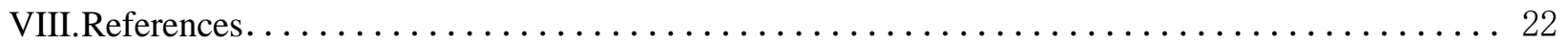




\section{General information}

Materials. The following chemicals were used in our research: 3-mercaptopropionic acid (Sigma-Aldrich, $\geq 99 \%$ ), 2,2-dimethoxy-2-phenylacetophenone (DMPA, Sigma-Aldrich, >99.0\%), hydrogen tetrachloroaurate trihydrate (Admas, $\geq 99.9 \%$ ), potassium chloroplatinate (Aldrich, 99.99\%), potassium chloropalladite (Energy Chemical), silver nitrate (Yonghua Chemical), dimethyl sulfoxide (DMSO, Macklin, > 99.8\%), sodium hydroxide (Sigma-Aldrich, >97.0\%), 1[3-(dimethylamino)propyl]-3-ethylcarbodiimide methiodide (EDC, Sigma-Aldrich), $\quad \mathrm{N}$ hydroxysuccinimide (NHS, Fluka, > 97\%), 5-aminofluorescein (5-AF, Sigma-Aldrich), sodium cyclopentadiene ( $\mathrm{NaCp}$, Sinopharm), tetrahydrofuran (THF, Sinopharm), sodium hydroxide $(\mathrm{NaOH}$, Sinopharm), and toluene. All of these chemicals were used as received without further purification. Chlorpromazine (CPZ), methyl- $\beta$-cyclodextrin (M $\beta \mathrm{CD})$, filipin III, and amiloride were purchased from Beijing Yinuokai Technology Co., Ltd. The monomer methyl vinyl[1]sila ferrocenophane was synthesized via a previously reported method $^{1}$. A549 cells (human nonsmallcell lung cancer cell lines) and HUVEC cells (human umbilical vein endothelial cells) were provided by the Chinese Academy of Sciences Stem Cell Bank. A549/Taxol drug-resistant cells were purchased from Oulu Biotechnology. Cell counting kit-8 (CCK-8) and 4',6-diamidino-2phenylindole (DAPI) were purchased from Beyotime Biotechnology. Calcein-AM/PI double stain kit was purchased from Yeasen Biotech.

Characterization. ${ }^{1} \mathrm{H}$ nuclear magnetic resonance (NMR) spectra were measured using an Avance III $600 \mathrm{MHz}$ NMR spectrometer. Gel permeation chromatography (GPC) was performed using a Viscotek VE 2001 Triple-Detector system that was equipped with styrene/divinylbenzene columns (pore sizes of between $500 \AA$ and 100,000 $\AA$ ). Calibration of the detectors was performed using polystyrene standards (Viscotek). MALDI-TOF mass spectrometry was performed using a Bruker Ultraflextreme system that was operated in the linear mode. Dynamic light scattering (DLS) and zeta potential measurements were performed using a Zetasizer Nano ZS90 instrument (Malvern, U.K.). Transmission electron microscopy (TEM) images were taken with a FEI Tecnai G2 Spirit BioTwin transmission electron microscope (120 kV, FEI, U.S.A.). High-angle annular 
dark-field scanning transmission electron microscopy (HADDF-STEM) images and energy dispersive spectroscopy (EDS) mapping images were captured with a TALOS F200X fieldemission scanning election microscope (200 kV, FEI, U.S.A.). UV-Vis spectra were recorded with a UV-2550 ultraviolet-visible spectrophotometer (Shimadzu, J.P.N.). Confocal laser scanning microscope images were obtained using a TCS SP8 STED 3X Super-resolution multiphoton confocal microscope (Leica, G.E.R.). Inductively coupled plasma-atomic emission spectrometry (ICP-AES) was performed with an iCAP7600 ICP-AES instrument (Thermo, U.S.A.). Cell uptake in endocytic pathway experiment was measured by a flow cytometer, Beckman Cytoflex FCM (LSRFortessa, BD, Franklin Lakes, NJ, U.S.A.).

\section{Experimental section}

Synthesis of PFMVS. The polymer was prepared via a previously reported photolytic ringopening polymerization (ROP) procedure ${ }^{2}$. A solution of methyl vinyl[1]sila ferrocenophane (3.385 g, $13.75 \mathrm{mmol}), \mathrm{NaCp}(59.2 \mu \mathrm{L}$ of a $2 \mathrm{M}$ THF solution, $0.118 \mathrm{mmol})$ and THF $(27.1 \mathrm{~mL})$ was irradiated for $20 \mathrm{~h}$ at $5{ }^{\circ} \mathrm{C}$. This reaction produced $2.850 \mathrm{~g}$ dark red gum. The yield was $84.2 \%$.

Synthesis of PFC. The hydrothiolation reaction was performed via a previous reported method $^{3}$. 2.850 g PFMVS was dissolved in $20 \mathrm{~mL}$ THF. 3-Mercaptopropionic acid (3.3 mL, 38 mmol) and DMPA (0.820 g, $3.20 \mathrm{mmol})$ were then added to this solution. The solution was then subjected to $2 \mathrm{~h}$ of photo-irradiation at $20^{\circ} \mathrm{C} .1 .998 \mathrm{~g}$ product in the form of a yellow solid was collected after it had been precipitated three times in methanol. The yield was 50.0\%.

Preparation of PFC micelles. The PFC polymer was dissolved in DMSO at the concentration of $10 \mathrm{mg} / \mathrm{mL}$ to provide a stock solution. This stock solution was then diluted to various concentrations $(1-10 \mathrm{mg} / \mathrm{mL})$. Subsequently, deionized water $(0.5$ or $1.2 \mathrm{~mL})$ was slowly injected $(1.2 \mathrm{~mL} / \mathrm{min})$ into $5 \mathrm{~mL}$ of each diluted solution with stirring. The stirring was continued for $12 \mathrm{~h}$ after the injection of the deionized water. Subsequently, the mixed solution was dialyzed against deionized water for 2 days in order to remove DMSO. 
Preparation of the Fluorescence decorated PFC micelles (Flr-PFC micelles). A $500 \mu \mathrm{L}$ DMSO solution of 5-AF (5 mg/mL, $14.4 \mathrm{mM})$ along with NHS (24.8 mg, $21.6 \mu \mathrm{mol})$ and EDC (21 mg, $7.2 \mu \mathrm{mol})$ were added into a $5 \mathrm{~mL}$ aqueous dispersion of PFC micelles $(5 \mathrm{mg} / \mathrm{mL})$. The solution was shielded from light and stirred for $24 \mathrm{~h}$. The reactants were subsequently removed via dialysis against deionized water for 2 days (the water was changed every $3 \mathrm{~h}$ ).

Preparation of the PFC/Au nanocomposites (NCs) and other PFC/Noble metal NCs. A PFC micelle dispersion was diluted to $1 \mathrm{mM}$ (in terms of the moles of repeating agents repeating units, $0.37 \mathrm{mg} / \mathrm{mL})$ for in situ preparation of AuNPs. $\mathrm{HAuCl}_{4}(25 \mathrm{mM})$, the gold precursor, was subsequently added into $2.5 \mathrm{~mL}$ PFC micelles solution. A $0.1 \mathrm{M}$ sodium hydroxide solution was used to adjust the $\mathrm{pH}$ of the solution to the range of $6 \sim 8$ as required. Distilled water was then added into the system to adjust the volume of the solution to $5 \mathrm{~mL}$. The reaction was allowed to continue for $12 \mathrm{~h}$ with stirring at room temperature. The resulting solution was then centrifuged $(12,000$ $\mathrm{r} / \mathrm{min}, 15 \mathrm{~min}$ ) and washed three times with water to remove the redundant reactants. PFC/Au NCs powder was thus obtained after drying in an oven. The powder was dispersed into deionized water to obtain a PFC/Au NC dispersion.

For other PFC/Noble metal NCs, almost the same method was performed. Firstly, $2.5 \mathrm{~mL} 1$ $\mathrm{mM}(0.37 \mathrm{mg} / \mathrm{mL}) \mathrm{PFC}$ dispersion was prepared. Then, $60 \mu \mathrm{L}$ noble metal precursor $\left(\mathrm{K}_{2} \mathrm{PdCl}_{4}\right.$ or $\mathrm{AgNO}_{3}$ or $\mathrm{K}_{2} \mathrm{PtCl}_{4}, 25 \mathrm{mM}$ ) was added into the PFC micelles solution. The reaction continued for $12 \mathrm{~h}$ with stirring at room temperature. The resulting solution was then dialyzed via dialysis bag (14 k) against deionized water for $24 \mathrm{~h}$. Deionized water was changed every $3 \mathrm{~h}$ in order to remove the excess precursor. According to the ICP results of PFC/Au-5N, PFC/Ag, PFC/Pt, and PFC/Pd nanocomposites. The efficiencies are calculated to be $99.7 \%$ for $\mathrm{Au}, 22.8 \%$ for $\mathrm{Ag}, 99.9 \%$ for $\mathrm{Pd}$, and $7.9 \%$ for Pt.

The reduction reactions between noble metal precursors and ferrocene $(\mathrm{Fc})$ compound were shown as following:

$$
A u C l_{4}^{-}+F c \leftrightarrow A u^{0}+F c^{+}+C l^{-}
$$




$$
\begin{gathered}
\mathrm{PdCl}_{4}^{2-}+\mathrm{Fc} \leftrightarrow P d^{0}+\mathrm{FC}^{+}+\mathrm{Cl}^{-} \\
\mathrm{Ag}^{+}+\mathrm{Fc} \leftrightarrow A g^{0}+F c^{+} \\
\mathrm{PtCl}_{4}^{2-}+\mathrm{Fc} \leftrightarrow P t^{0}+\mathrm{FC}^{+}+\mathrm{Cl}^{-}
\end{gathered}
$$

Photothermal properties. The photothermal properties of the PFC/Au NCs were evaluated by measuring temperature changes under irradiation. Specifically, $2 \mathrm{~mL}$ of a $5 \mathrm{mM} \mathrm{PFC/Au} \mathrm{NCs}$ dispersion was placed in a $3 \mathrm{~mL}$ cuvette and then irradiated with a laser at $808 \mathrm{~nm}\left(2 \mathrm{~W} / \mathrm{cm}^{2}\right)$. Temperature changes were then recorded via a thermocouple that was immersed in the $\mathrm{PFC} / \mathrm{Au}$ $\mathrm{NC}$ dispersion.

The equation used to calculate the photothermal conversion efficiency $(\eta)$ was given as following 4 :

$$
\eta=\frac{h A \Delta T_{\max }-Q_{\mathrm{s}}}{I\left(1-10^{-A_{\lambda}}\right)}
$$

where $h$ represents the heat transfer coefficient of the solvent, $A$ represents the surface area of the container, $\Delta T$ represents the change of temperature, $Q$ s represents the heat offered by the light absorbance of the solvent, $I$ represents the laser power, $A_{\lambda}$ represents the absorbance of the solution at wavelength $\lambda$. As the only unknown part in equation (1), $h A$ can be calculated via following equation:

$$
h A=\frac{m C}{\tau}
$$

where $m$ means the mass of solvent, $C$ is the heat capacity of solvent. $\tau$ is the sample system time constant which is directly related to $\theta$ by

$$
\tau=-\frac{t}{\ln \theta}
$$

where $t$ is the cooling time of the system and $\theta$ is defined as ratio of $\Delta T$ to $\Delta T_{\max }$ :

$$
\theta=\frac{\Delta T}{\Delta T_{\max }}
$$


Cellular viability. A549 and A549/Taxol cells were cultured in a 96-well plate for $24 \mathrm{~h}$. PFC NMs and PFC/Au NMs were incubated with the cells for $48 \mathrm{~h}$. Subsequently, laser irradiation (808 $\mathrm{nm}, 2 \mathrm{~W} / \mathrm{cm}^{2}$ ) was performed for $5 \mathrm{~min}$ after the samples had been incubated. The cellular viabilities were then measured by CCK- 8 cell viability assays.

Cellular endocytosis experiments. A549 cells were cultured in a 12-well plate for $24 \mathrm{~h}$. FlrPFC NMs and PFC/Au NMs were incubated with these cells for $4 \mathrm{~h}$. The cells were then fixed by a 4\% paraformaldehyde solution and stained with DAPI. The cells were subsequently observed using a confocal laser scanning microscope. The concentration of gold ingested by the A549 cells was measured via ICP-AES.

Endocytic pathway of PFC micelles. Endocytic pathway experiment was carried out using a similar method in our previous research ${ }^{5}$. A549 cells were plated in a $24-w e l l$ plate. Then, the A549 cells were pretreated separately with M $\mathrm{CD}(7.5 \mathrm{mM})$ for $15 \mathrm{~min}$, filipin III $(1 \mu \mathrm{g} / \mathrm{mL})$ for $30 \mathrm{~min}, \mathrm{CPZ}(10 \mu \mathrm{g} / \mathrm{mL})$ for $15 \mathrm{~min}$, and amiloride $(25 \mu \mathrm{g} / \mathrm{mL})$ for $1 \mathrm{~h}$. Subsequently, the pretreated cells were incubated with Flr-PFC micelles $(30 \mu \mathrm{g} / \mathrm{mL})$ for $1 \mathrm{~h}$. The cells were harvested and analyzed on a flow cytometer. 


\section{Characterization of PFMVS98}
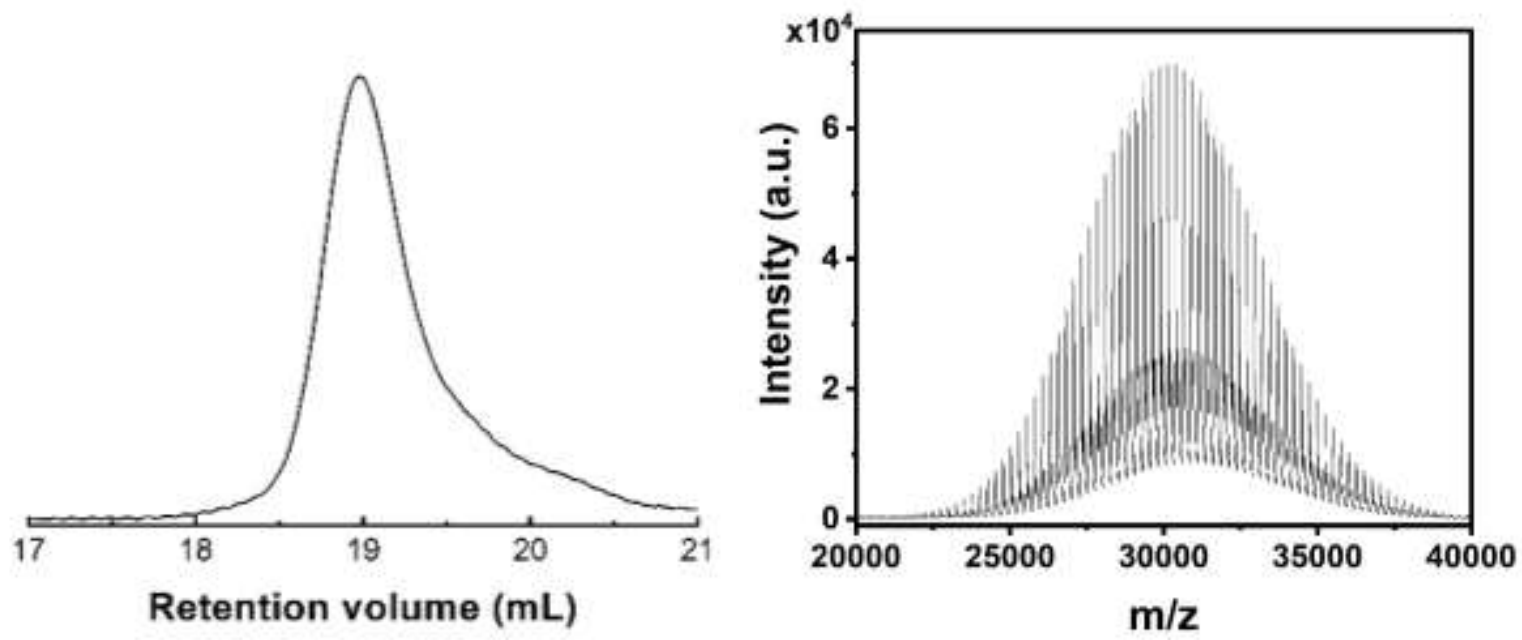

Figure S1. GPC trace and MALDI-TOF mass spectrum of PFMVS 98. 


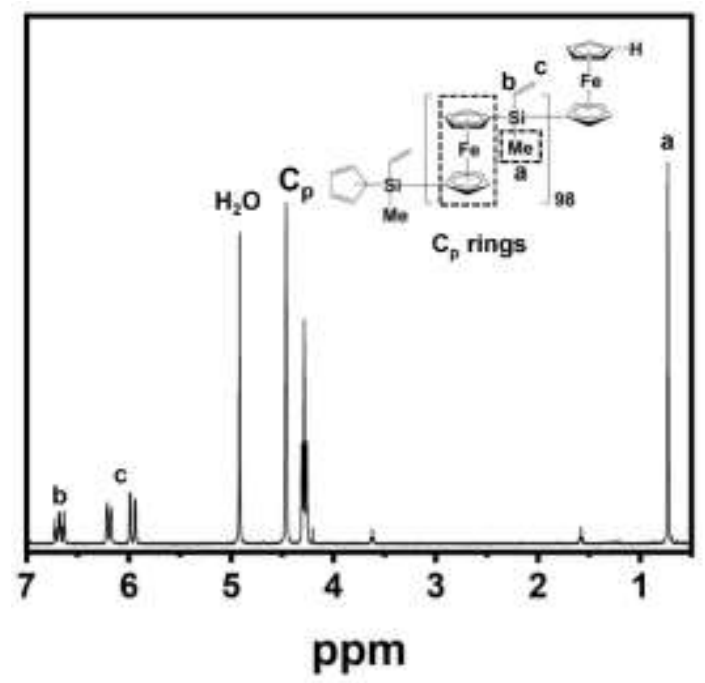

Figure S2. ${ }^{1} \mathrm{H}$ NMR spectrum of $\mathrm{PFMVS}_{98}, \mathrm{CD}_{3} \mathrm{OD}$ was used as the solvent. 
IV. Characterization of PFC and the PFC micelles

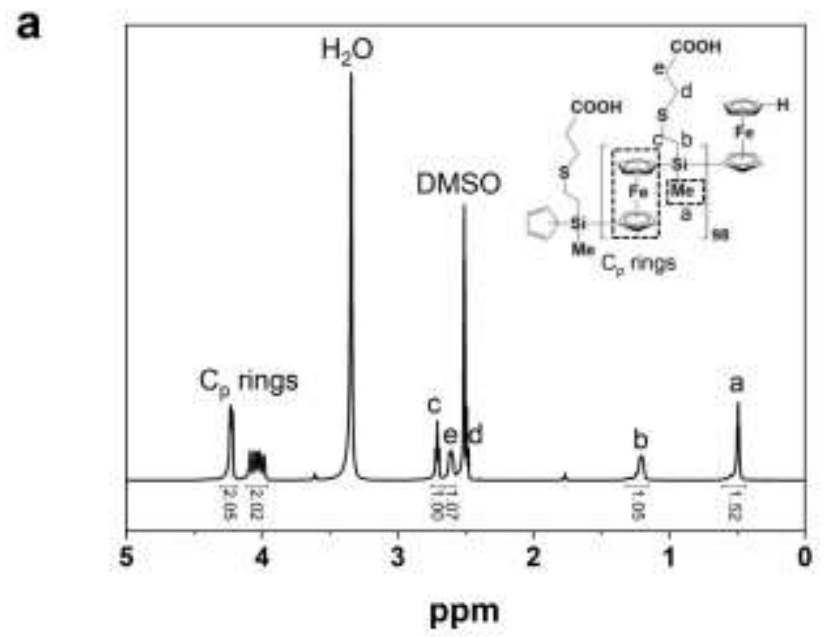

b

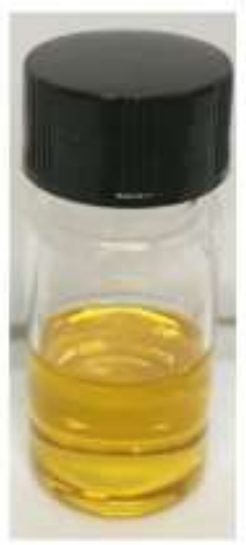

Figure S3. a, ${ }^{1} \mathrm{H}$ NMR spectrum of $\mathrm{PFC}_{98}$, d6-DMSO was used as the solvent. b, Appearance an aqueous dispersion of $\mathrm{PFC}_{98}(2 \mathrm{mg} / \mathrm{mL})$. 

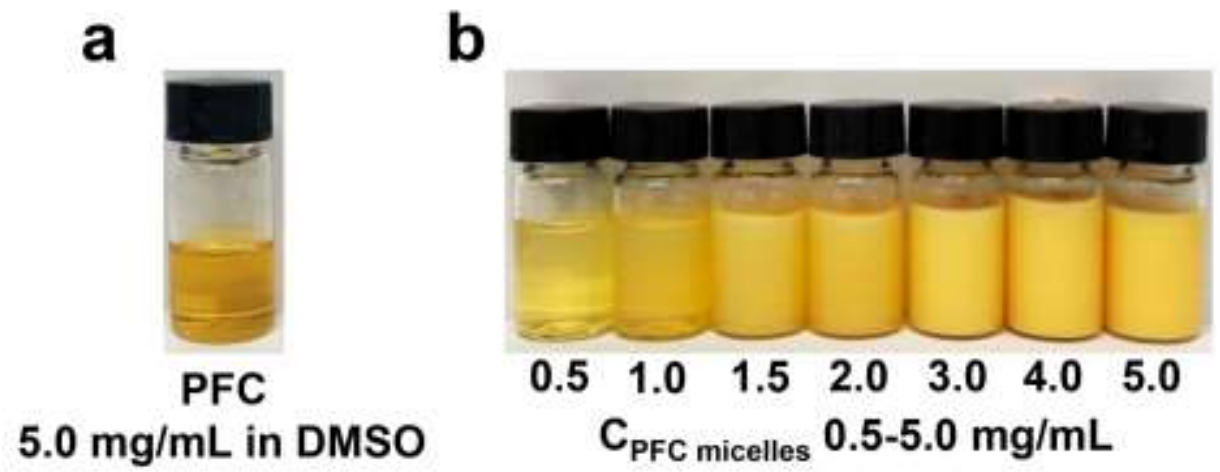

Figure S4. a, Appearance of a DMSO solution of PFC $(5.0 \mathrm{mg} / \mathrm{mL})$. b, Appearance of aqueous dispersions of the PFC micelles prepared with various concentrations of PFC $(1-10 \mathrm{mg} / \mathrm{mL})$ in DMSO/water solvent mixtures with $9.1 \mathrm{wt} \%$ water (the concentration of obtained PFC micelles was diluted to half of the original concentration of PFC because of the increase of the volume during the dialyze procedure). 

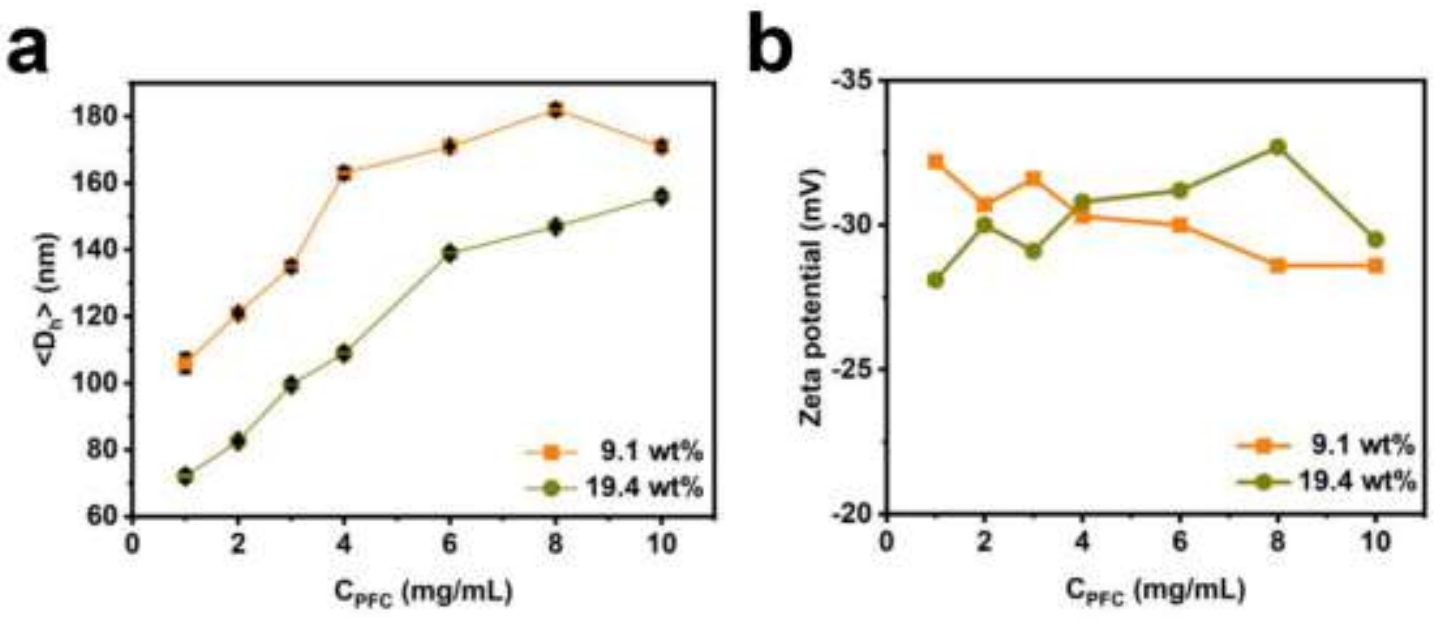

Figure S5. a, Variation of the hydrodynamic diameter of PFC micelles aqueous dispersion against $\mathrm{C}_{\mathrm{PFC}}$ of PFC micelles prepared in DMSO/water solvent mixtures with 9.1 and 19.4 wt\% water. b, Zeta potentials of PFC micelles aqueous dispersion prepared with different parameters. 


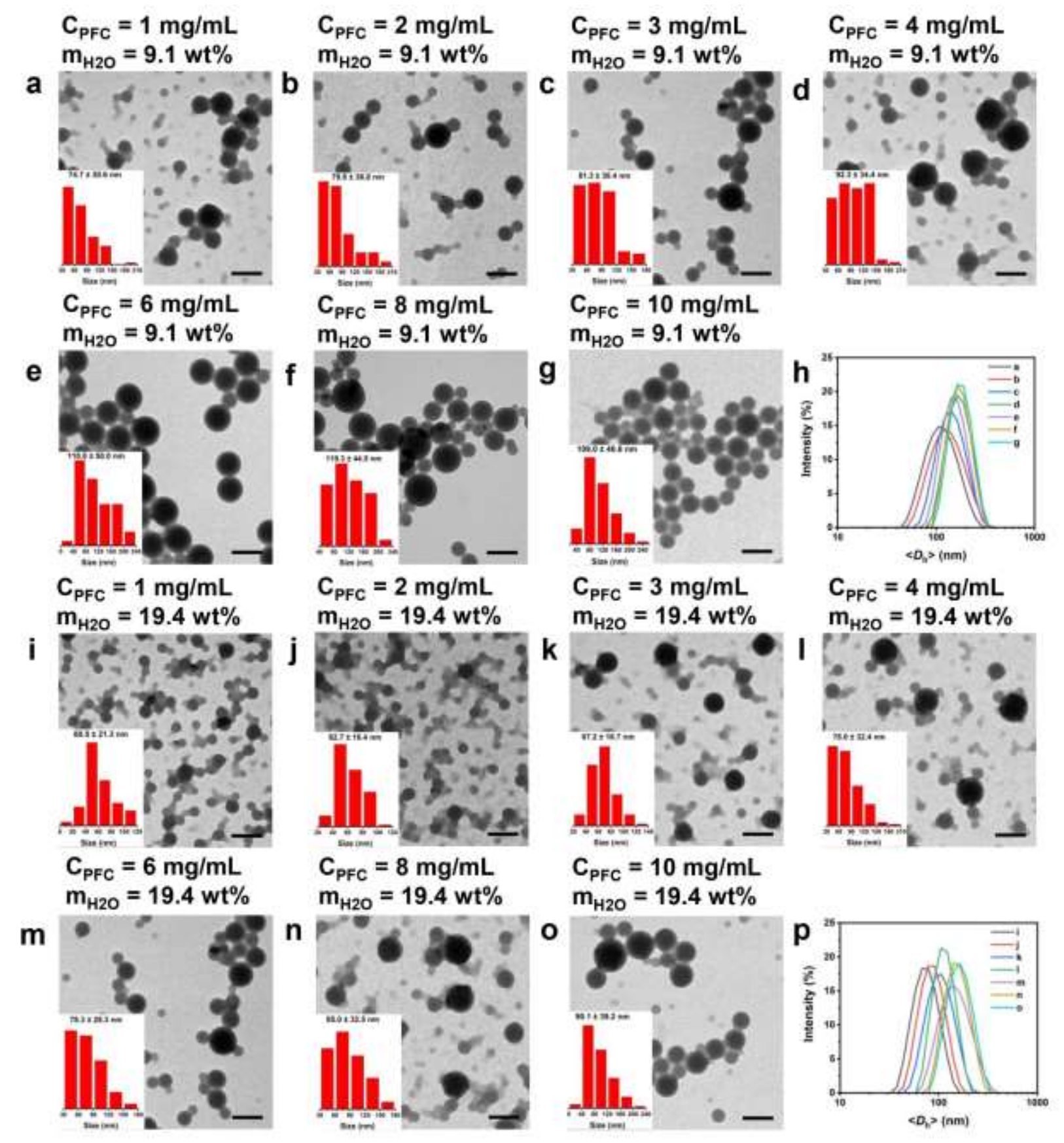

Figure S6. Size control of the PFC micelles. a-g, TEM images of PFC micelles prepared in DMSO/water solvent mixtures with $9.1 \mathrm{wt} \%$ water. $\mathbf{h}$, Hydrodynamic diameter distribution of samples in a-g. i-o, TEM images of PFC micelles prepared in DMSO/water solvent mixtures with $19.4 \mathrm{wt} \%$ water. p, Hydrodynamic diameter distribution of samples in i-o. Scale bars: $200 \mathrm{~nm}$. 


\section{Cellular viability of the PFC micelles}
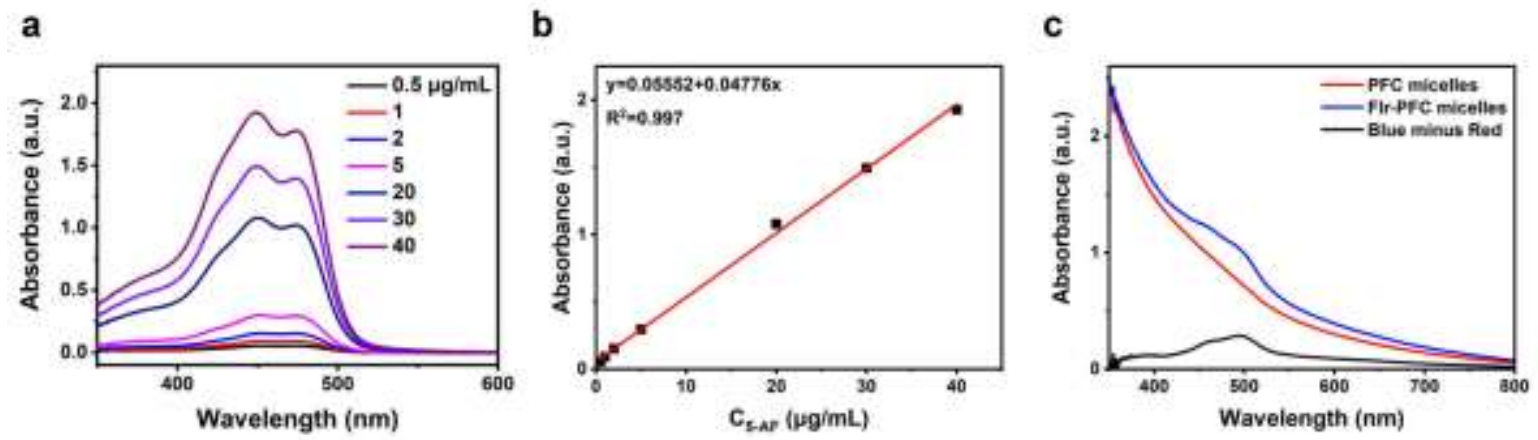

Figure S7. 5-AF decoration of the PFC micelles. a, UV-Vis spectra of 5-AF at various concentrations in a mixed solution comprised of $90 \% \mathrm{H}_{2} \mathrm{O}$ and $10 \%$ DMSO. b, Calibration curve based on the absorbance at $449 \mathrm{~nm}$ versus the concentration of 5-AF. c, UV-Vis spectra of PFC micelles before and after 5-AF modification in the mixed solution. 


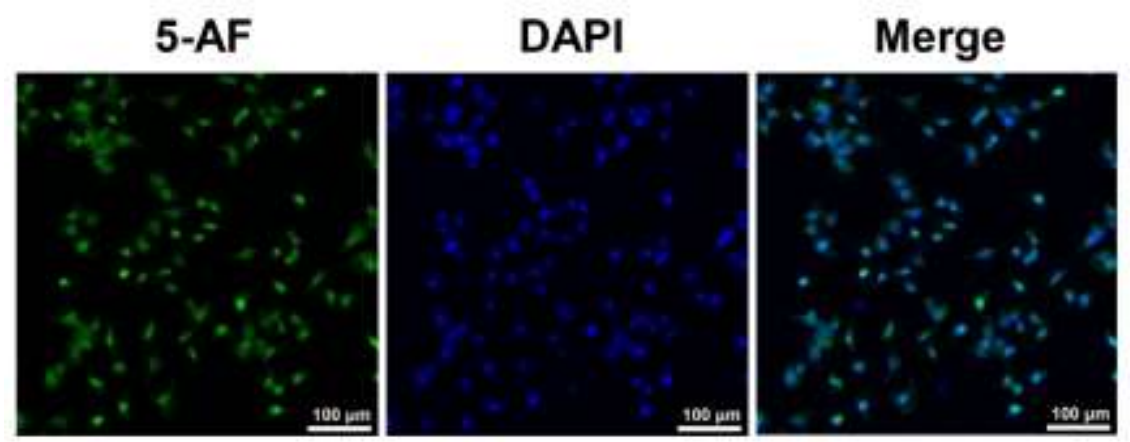

Figure S8. Confocal laser scanning microscope images of Flr-PFC micelles (modified with 5-AF) after incubation with A549 cells for $4 \mathrm{~h}$. 


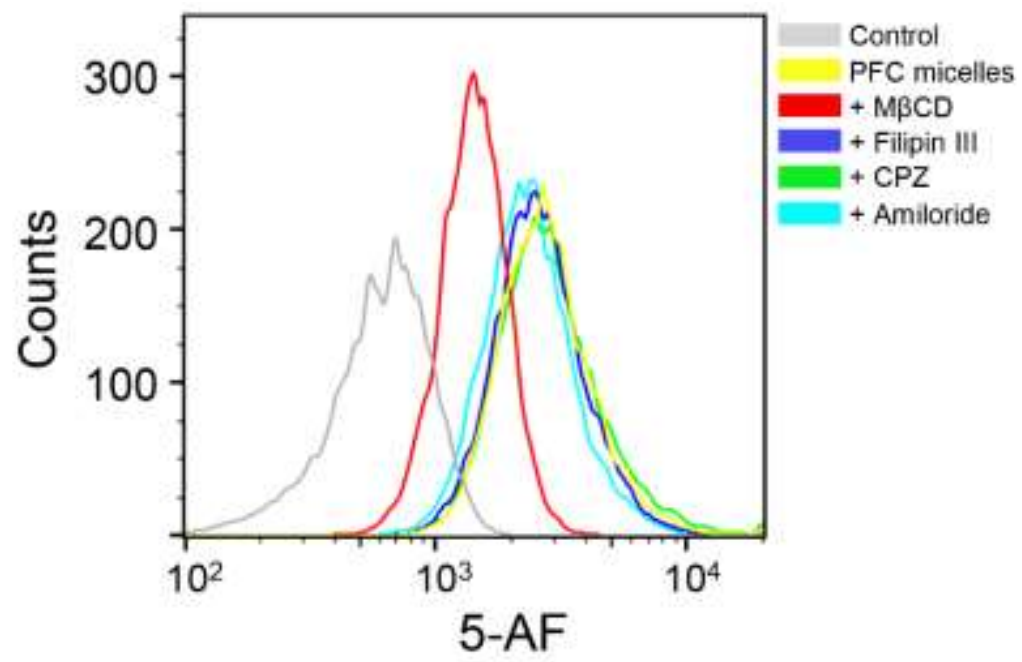

Figure S9. Flow cytometry analysis of the effect of endocytosis inhibitors on cellular uptake of Flr-PFC micelles (modified with 5-AF) in A549 cells. 


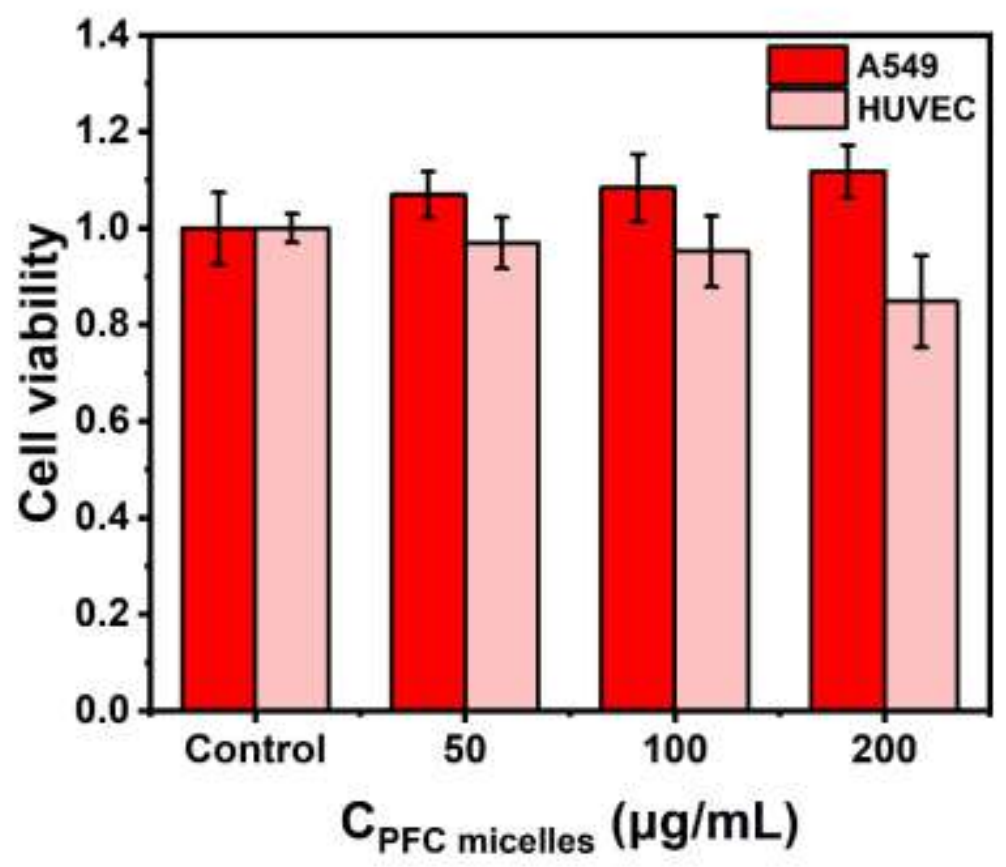

Figure S10. Cell viabilities of A549 cells and HUVEC cells after incubation with PFC micelles for $48 \mathrm{~h}$. 


\section{Morphologies of the PFC/Au NCs}
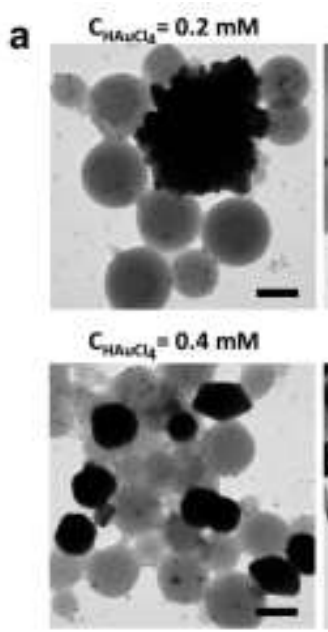

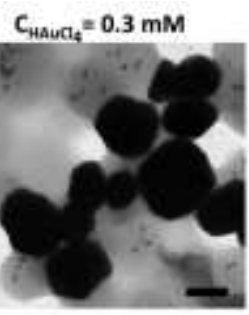

$C_{\text {HAuClq }}=0.5 \mathrm{~mm}$

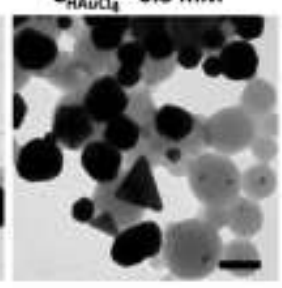

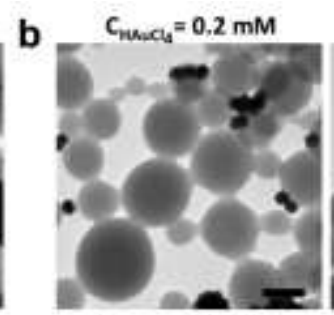

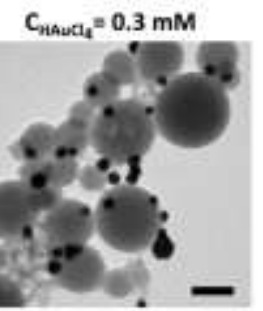

$C_{\text {rand }}=0.4 \mathrm{mM}$

$C_{\text {HAud }}=0.5 \mathrm{mM}$

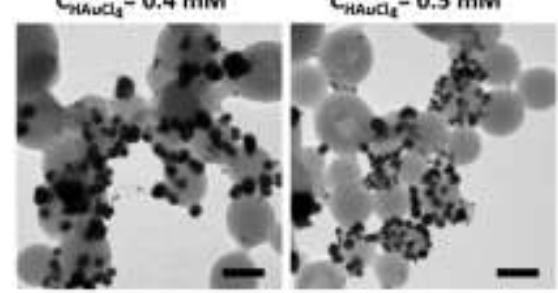

Figure S11. TEM images of PFC/Au NCs prepared under different conditions. a, TEM images of PFC/Au NCs prepared at different $\mathrm{C}_{\mathrm{HAuCl} 4}$ in acidic media. $\mathbf{b}$, TEM images of PFC/Au NCs prepared at different $\mathrm{C}_{\mathrm{HAuCl} 4}$ in neutral media. Scale bars: $100 \mathrm{~nm}$. 

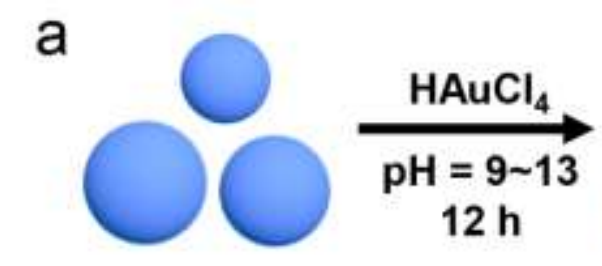

PFC micelles
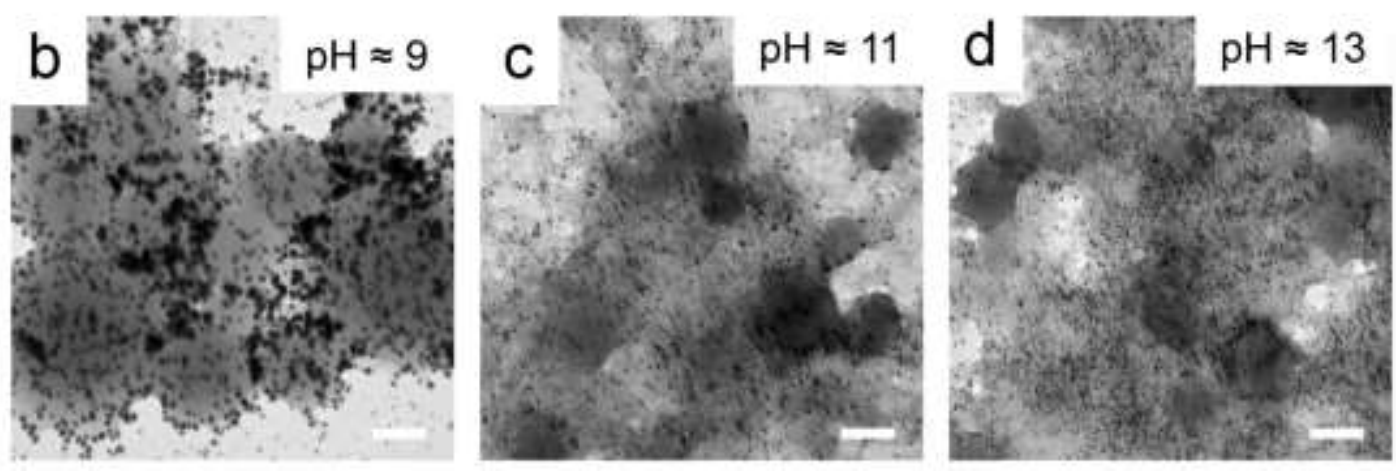

Figure S12. Preparation of PFC/Au NCs in alkaline media. a, Schematic illustration depicting the fabrication of PFC/Au in alkaline media. b, TEM images of PFC/Au NCs prepared at different pH value. Scale bars: $100 \mathrm{~nm}$. 


\section{Photothermal properties of the PFC/Au NCs}

a

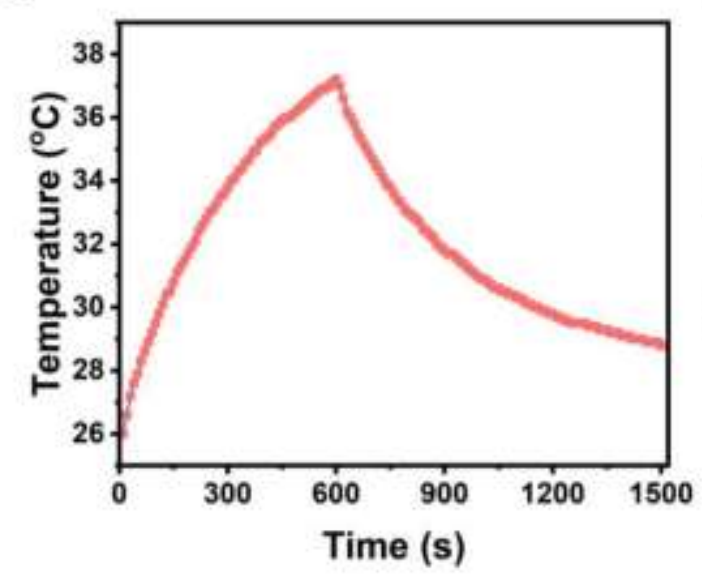

b

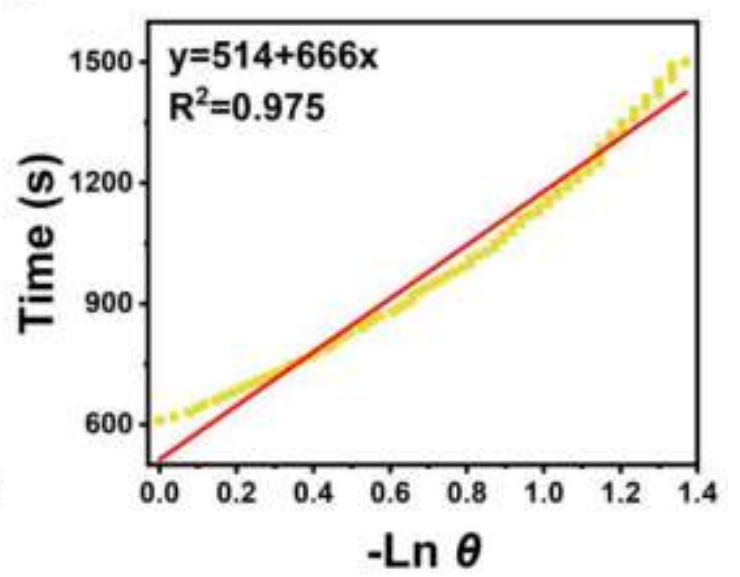

Figure S13. a, Temperature change exhibited by the $\mathrm{PFC} / \mathrm{Au}-5 \mathrm{~A}$ dispersion in response to irradiation by an $808 \mathrm{~nm}$ laser $\left(2.0 \mathrm{~W} / \mathrm{cm}^{2}\right)$. b, Plot of the cooling time versus $-\ln \theta$. (Photo thermal conversion efficiency $=8.0 \%$ ) 


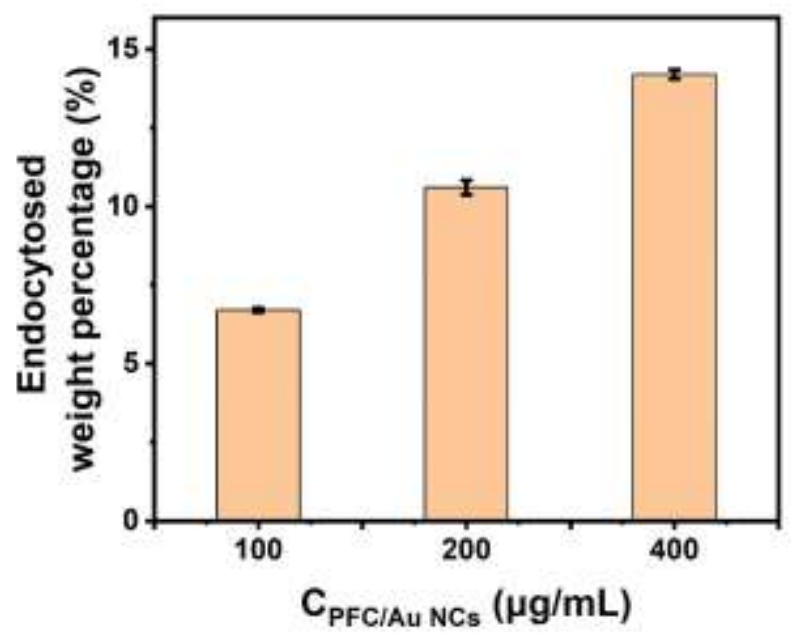

Figure S14. Endocytosed weight percentages of PFC/Au-5N NCs after $4 \mathrm{~h}$ incubation. These percentages were calculated based on ICP-AES data. 


\section{References}

1. Zechel, D. L.; Hultzsch, K. C.; Rulkens, R.; Balaishis, D.; Ni, Y.; Pudelski, J. K.; Lough, A. J.; Manners, I.; Foucher, D. A., Thermal and Transition-Metal-Catalyzed Ring-Opening Polymerization (ROP) of [1]Silaferrocenophanes with Chlorine Substituents at Silicon: A Route to Tunable Poly(ferrocenylsilanes). Organometallics. 1996, 15 (8), 1972-1978.

2. Tanabe, M.; Manners, I., Photolytic Living Anionic Ring-Opening Polymerization (ROP) of Silicon-Bridged [1] Ferrocenophanes via an Iron-Cyclopentadienyl Bond Cleavage Mechanism. J. Am. Chem. Soc. 2004, 126 (37), 11434-11435.

3. Chabanne, L.; Pfirrmann, S.; Lunn, D. J.; Manners, I., Controlled Thiol-Ene PostPolymerization Reactions on Polyferrocenylsilane Homopolymers and Block Copolymers. Polym. Chem. 2013, 4 (7), 2353-2360.

4. Liu, Y.; Ai, K.; Liu, J.; Deng, M.; He, Y.; Lu, L., Dopamine-Melanin Colloidal Nanospheres: An Efficient Near-Infrared Photothermal Therapeutic Agent for In Vivo Cancer Therapy. Adv. Mater. 2013, 25, 1353-1359.

5. Liu, L.; Xu, Y.; Zhang, P.; You, J.; Li, W.; Chen, Y.; Li, R.; Rui, B.; Dou, H., High-Order Assembly toward Polysaccharide-Based Complex Coacervate Nanodroplets Capable of Targeting Cancer Cells. Langmuir. 2020, 36, 8580-8588. 